\title{
The Surface Layer on the Leeside of the Alps during Foehn
}

\author{
K. P. Hoinka and F. Rösler
}

With 13 Figures

Received January 26, 1987

Revised April 16, 1987

\begin{abstract}
Summary
This paper describes and documents the meteorological conditions which occur in association with a cold surface layer on the northern lee side of the Alps during foehn. A climatological study using four years' rawinsonde data shows that during many foehn events a weak advection from the east occurs in the cold surface layer beneath the southerly foehn flow. Three cases of foehn in the northern Alps were studied using data taken by instrumented aircraft. The analysis of various vertical soundings between the baseline of the Alps and Munich indicate that the cold surface layer is eroded up to $50 \mathrm{~km}$ north of the baseline but that further north, the foehn has not touched the ground. The analysis of data taken in the urban plume west of Munich shows that the pollution is trapped by the inversion in the cold air leading to high levels of air pollution west of Munich.
\end{abstract}

\section{Introduction}

Some downslope winds occurring north of the Alps were called foehn as soon as they are linked with strong gusty winds and with an increase in temperature. One factor is of great importance for this warming: suppose the region north of the Alps is covered by a high pressure area involving a cold air mass, then during foehn this regime of cold air at ground level north of the Alps is invaded from above by the warmer foehn air which has crossed the Alps. Usually, this cold air during foehn is the remainder of cold air transported from polar regions towards the Alps. But a pool of cold air also forms when the absence of clouds permits the ground to radiate freely towards space. This cooling mainly affects a shallow layer with the result that the surface temperatures do not represent a layer of any appreciable depth.

Between the two air masses, the surface based cold air and the warm foehn air, strong inversions occur with temperature changes of up to $15 \mathrm{~K}$ across these interfaces within $100 \mathrm{~m}$ (Nater et al., 1979). A temperature inversion in the atmosphere gives a layer that suppresses the transfer of heat, momentum, and minor constituents such as pollution products or water vapor. Particularly in industrial and urban areas these low level inversions act as effective barriers against vertical exchanges, leading to high levels of pollution. Nkemdirim and Leggat (1978) showed that the air quality at Calgary during chinook is two to four times as bad as during non-chinook weather. This provides support for the idea that the inversions during chinook are very efficient in trapping pollutants. Rush hour traffic frequently raises the concentrations of pollutants in Munich. Due to these strong inversions in Munich, just as in Calgary, the air is very polluted during foehn.

Regions where two different air masses converge at the surface during strong downslope wind events are known from the Rocky Mountains in U.S.A. and Canada (Bedard, 1982; Holmes and Hage, 1971) and north of the Alps. To study how 
the foehn erodes the stable layer one possible way is to use a mesoscale model with vertical eddy mixing processes and gravity wave flux parameterisation. Before doing this, the behaviour of the cold surface layer must be studied, using observational data, because this has not been done sufficiently. The purpose of the present study is to document the surface based stable layer north of the Alps during foehn. This includes the determination of: the meso-scale lee-side circulation during foehn; the spatial behaviour of the lowlevel inversion between the baseline of the Alps and Munich; and finally the air pollution trapped beneath this inversion.

In order to achieve all three tasks during one event one would need several aircraft. However, for the present study only one Queenair and two motorgliders were available. Therefore, the necessary measurements were made on three different days with south-foehn, all associated with a surface based cold layer. On October 22, 1982 measurements were made to determine the meso-scale circulation; on December 16, 1983 flights were made to determine the behaviour of the inversion between the baseline of the Alps and Munich; and finally on October 13, 1984 the Queenair equipped with pollution measurement systems made datagathering flights in the low-level layer west of Munich.

There is observational evidence that advection to the west occurs in the surface based cold air at the northern side of the Alps. In order to determine the climatological characteristics of the low-level flow above Munich during foehn in relation to the synoptic flow we consider wind statistics of a four years' sample of rawinsonde data taken at Munich.

The first section contains a comparison of the surface wind with the mid-tropospheric wind observation for Munich for a period of four years. The next section contains a brief description of the synoptic features of the three foehn days. The following three sections discuss in detail the analysis of the low-level lee circulation; the behaviour of the low-level inversion; and the trapping of polluted air beneath this inversion.

\section{The Wind Observations in Munich}

Because two different air masses converge at the surface during foehn, one would expect different flow features near the ground than at upper levels. In this section we compare the observed surface wind in Munich with the upper level geostrophic wind. The wind at $500 \mathrm{mb}$, taken from rawinsondes, is considered to be the geostrophic wind.

The data set consists of a four year sample of rawinsonde data taken at Munich at $1200 \mathrm{GMT}$. It is split into two subsamples: one containing all days with foehn, the other containing all days without foehn. Because there are no long-term statistics on foehn occurrence at Munich, we use observations at Innsbruck to decide whether it was a day with foehn or not. The meteorological observer registers south foehn every day as weak, moderate or strong according to the violence of the foehn. Strong foehn means that there are violent winds from the south observed at ground level together with strong gustiness. Additionally increasing temperature, decreasing relative humidity and decreasing cloudiness occur along with excellent visibility and the appearance of a foehn wall above the Brenner Pass, which is the main divide of the Alps. The frequency distribution of the wind at $500 \mathrm{mb}$ (full line) and that at the surface (dashed line) is presented in Fig. 1 (top). The figure shows the percentage of each wind direction. The distribution of the wind at $500 \mathrm{mb}$ emphasizes the apparent west wind belt characteristic. The structure of the windrose suggests that the Alps channel the wind to some extent.

On days with foehn in the Alps, the distribution of the wind direction is quite different, as shown in Fig. 1 (bottom). The number of wind observations with foehn is about 184 , which is about $13 \%$ of the total number of usable observations (1434) during the four year period. At $500 \mathrm{mb}$ the main wind direction shifts to the southwest. In many cases the surface wind comes from the east. This confirms the easterly advection of air in the cold surface layer. Over flat terrain without orographic irregularities the surface wind should be turned by about $30^{\circ}$ to the left of the geostrophic wind by surface friction. However, in the present case the differences in surface wind and geostrophic wind are due to the fact that both winds occur in different air masses separated by an inversion.

There are even some foehn events with flow at $500 \mathrm{mb}$ from west to north-west. This needs an explanation because the Alps are located south of Munich and Innsbruck. Two general types of 

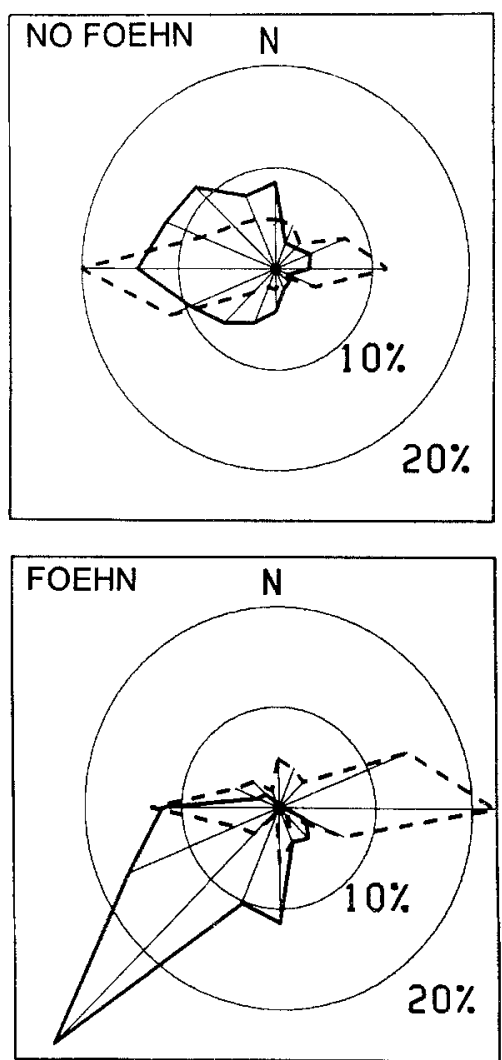

Fig. 1. Frequency distributions of the wind directions at $\mathrm{Mu}-$ nich: surface wind (broken line) and wind at $500 \mathrm{mb}$ (full line). The sample used for the top figure consists of all days without foehn and that for the bottom figure of all days with foehn, both from the period 1974-1977

foehn exist, the classical foehn with a fairly deep southwesterly flow aloft and a shallow foehn which is characterized by low-level southerly winds up to $700 \mathrm{mb}$ topped by a layer where westerly winds prevail.

The dependency of the surface wind on the geostrophic wind can be seen even better in Fig. 2. It shows isolines of the frequency of occurrence $(\%)$, for the direction of the geostrophic wind, and for the corresponding direction of the surface wind. Of course, the observed surface winds have different directions for the same direction of the geostrophic wind; this may be due to different speeds of the geostrophic wind and different stratification.

In case of no foehn (Fig. 2, top), there is a strong maximum of about $3.9 \%$ at $270^{\circ}(500 \mathrm{mb}$ and surface) and another smaller maximum $(1.1 \%)$ is found at $90^{\circ}$ (surface) and $270^{\circ}(500 \mathrm{mb}$ ). Another maximum can be seen in case of both winds from the east $(1.3 \%)$. However, during foehn this sit-

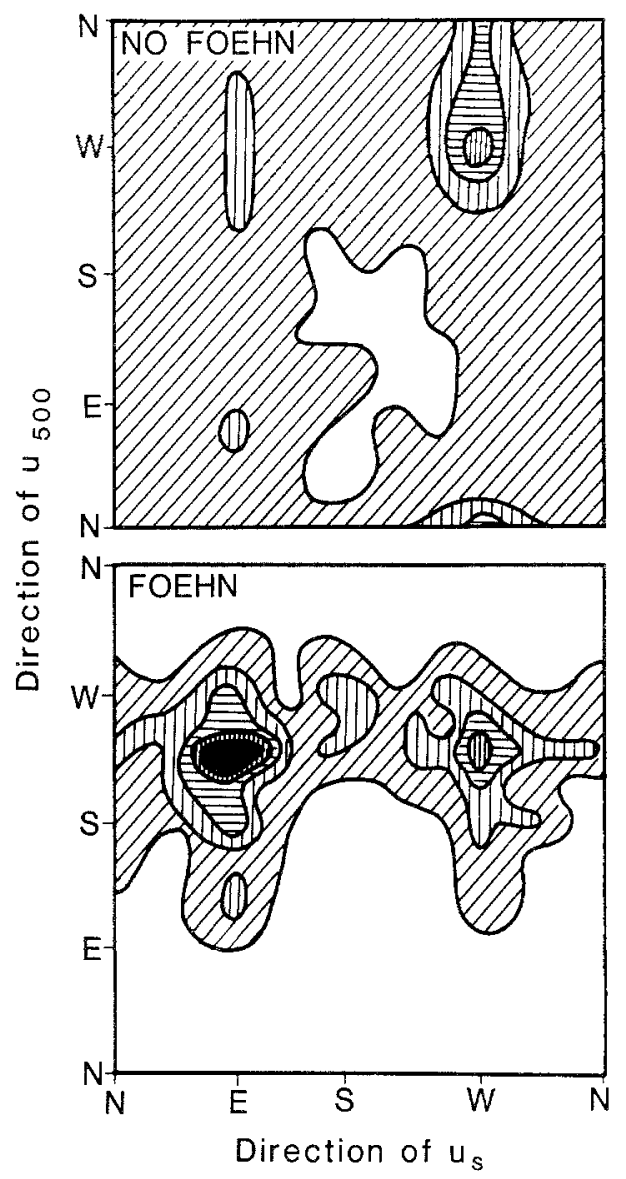

Fig. 2. Iso-lines for the relative frequency ( $\%$ ) of the surface wind $u_{s}$ direction (within a range of $22.5^{\circ}$ ) associated with a given direction of the $500 \mathrm{mb}$ wind $u_{500}$. The sample used for the top figure consists of all days without foehn and that for the bottom figure of all days with foehn, both from the period 1974-1977. The indicated areas are shaded as follows: $\square$ $0 \%$, 0-1\%, 四 1-2\%, 2-3\%, 四 3-4\%, 4-7\%

uation is changed (Fig. 3, bottom). A strong maximum of about $6.7 \%$ is found with surface winds from $90^{\circ}$ and $3.6 \%$ with surface winds from $270^{\circ}$ ( $500 \mathrm{mb}$ wind from southwest). The foehn air only touches the ground in some cases, namely when the surface and $500 \mathrm{mb}$ wind direction is between southeast and southwest. The magnitude of its occurrence is about $6 \%$. This structure of the isolines of relative frequency of the surface wind direction associated with a given direction of the geostrophic wind makes it very clear that in most cases the foehn air has not reached the surface at Munich (with surface winds from $\mathrm{E}$ to $\mathrm{N}$ ).

For completeness, Table 1 gives the averaged wind speeds for each direction, both at the surface and at $500 \mathrm{mb}$. During foehn most mean wind speeds increase significantly at the $500 \mathrm{mb}$ level. 
Table 1. The Averaged Speed of the Surface and $500 \mathrm{mb}$ Wind (within a range of $22.5^{\circ}$ ) at Munich on Days with and without Foehn Between 1974-1977. The winds are taken at 1200 GMT

\begin{tabular}{|c|c|c|c|c|c|c|c|c|}
\hline & \multicolumn{8}{|c|}{ No foehn } \\
\hline & NNE & $\mathrm{NE}$ & ENE & E & ESE & $\mathrm{SE}$ & SSE & S \\
\hline $\begin{array}{l}\text { Surface } \\
\text { Sample }\end{array}$ & 2.2 & 2.5 & 3.2 & $\begin{array}{r}3.1 \\
122\end{array}$ & $\begin{array}{l}2.3 \\
48\end{array}$ & 2.5 & 2.3 & $1.6 \mathrm{~m} / \mathrm{s}$ \\
\hline \multirow{3}{*}{$\begin{array}{l}500 \mathrm{mb} \\
\text { Sample }\end{array}$} & 140 & 112 & 120 & 102 & 93 & 100 & 14 & 21 days \\
\hline & 29 & 31 & 41 & $\begin{array}{c}10.2 \\
37\end{array}$ & 15 & $\begin{array}{c}10.0 \\
20\end{array}$ & $\begin{array}{l}10.7 \\
23\end{array}$ & $\begin{array}{c}9.4 \mathrm{~m} / \mathrm{s} \\
44 \text { days }\end{array}$ \\
\hline & SSW & SW & WSW & W & WNW & NW & NNW & $\mathrm{N}$ \\
\hline $\begin{array}{l}\text { Surface } \\
\text { Sample }\end{array}$ & $\begin{array}{l}2.4 \\
20\end{array}$ & $\begin{array}{l}3.2 \\
35\end{array}$ & $\begin{array}{c}5.3 \\
125\end{array}$ & $\begin{array}{c}4.9 \\
212\end{array}$ & $\begin{array}{l}3.5 \\
87\end{array}$ & $\begin{array}{l}3.2 \\
64\end{array}$ & $\begin{array}{l}2.2 \\
56\end{array}$ & $\begin{array}{c}1.7 \mathrm{~m} / \mathrm{s} \\
52 \text { days }\end{array}$ \\
\hline \multirow[t]{3}{*}{$\begin{array}{l}500 \mathrm{mb} \\
\text { Sample }\end{array}$} & $\begin{array}{l}12.3 \\
61\end{array}$ & $\begin{array}{l}13.5 \\
79\end{array}$ & $\begin{array}{l}14.4 \\
101\end{array}$ & $\begin{array}{l}15.5 \\
151\end{array}$ & $\begin{array}{l}15.2 \\
129\end{array}$ & $\begin{array}{l}14.9 \\
122\end{array}$ & $\begin{array}{l}15.9 \\
83\end{array}$ & $\begin{array}{l}15.2 \mathrm{~m} / \mathrm{s} \\
91 \text { days }\end{array}$ \\
\hline & \multicolumn{8}{|l|}{ Foehn } \\
\hline & NNE & $\mathrm{NE}$ & ENE & $\mathrm{E}$ & ESE & SE & SSE & $\mathrm{S}$ \\
\hline $\begin{array}{l}\text { Surface } \\
\text { Sample }\end{array}$ & $\begin{array}{l}1.9 \\
7\end{array}$ & $\begin{array}{l}2.0 \\
6\end{array}$ & $\begin{array}{l}2.6 \\
24\end{array}$ & $\begin{array}{l}2.6 \\
37\end{array}$ & $\begin{array}{l}3.1 \\
12\end{array}$ & $2^{1.8}$ & $\begin{array}{l}3.1 \\
6\end{array}$ & $\begin{array}{l}2.4 \mathrm{~m} / \mathrm{s} \\
9 \text { days }\end{array}$ \\
\hline \multirow{3}{*}{$\begin{array}{l}500 \mathrm{mb} \\
\text { Sample }\end{array}$} & - & - & - & - & 9.7 & 11.9 & 9.4 & $12.3 \mathrm{~m} / \mathrm{s}$ \\
\hline & 0 & 0 & 0 & 0 & 5 & 7 & 6 & 19 days \\
\hline & SSW & SW & Wsw & W & WNW & NW & NNW & $\mathrm{N}$ \\
\hline $\begin{array}{l}\text { Surface } \\
\text { Sample }\end{array}$ & $\begin{array}{l}1.5 \\
1\end{array}$ & $\begin{array}{l}3.3 \\
6\end{array}$ & $\begin{array}{l}4.6 \\
7\end{array}$ & $\begin{array}{l}2.8 \\
22\end{array}$ & $8^{2.9}$ & $6^{2.3}$ & $\begin{array}{l}1.7 \\
3\end{array}$ & $\begin{array}{l}1.6 \mathrm{~m} / \mathrm{s} \\
8 \text { days }\end{array}$ \\
\hline $500 \mathrm{mb}$ & 14.2 & 16.1 & 17.7 & 18.3 & 11.9 & 11.0 & - & $-\mathrm{m} / \mathrm{s}$ \\
\hline Sample & 17 & 55 & 28 & 20 & 4 & 2 & 0 & 0 days \\
\hline
\end{tabular}

The surface wind maximum is $4.6 \mathrm{~m} \mathrm{~s}^{-1}$ from west-south-west. At the frequency maximum (between ENE and ESE) the mean wind velocity is $3.1 \mathrm{~m} \mathrm{~s}^{-1}$.

From the synoptic charts it is clear that at $500 \mathrm{mb}$ the wind comes from southerly directions. However, there is still the question of why there is an advection from the east with an averaged wind speed of $3.1 \mathrm{~m} \mathrm{~s}^{-1}$ in the cold surface layer. The characteristic low-level charts show the typical mesoscale low in the cold surface layer (see Fig. 4). Associated with this trough is a gradient in surface pressure pointing northeastwards. Fig. 3 shows the spatial distribution of the averaged surface pressure gradients between Munich and its surroundings during foehn. The period chosen is similar to the one above. One can see a horizontal pressure gradient pointing towards northeast. Its magnitude is about $1.3 \mathrm{mb}$ per $100 \mathrm{~km}$. This significant pressure gradient causes the advection of

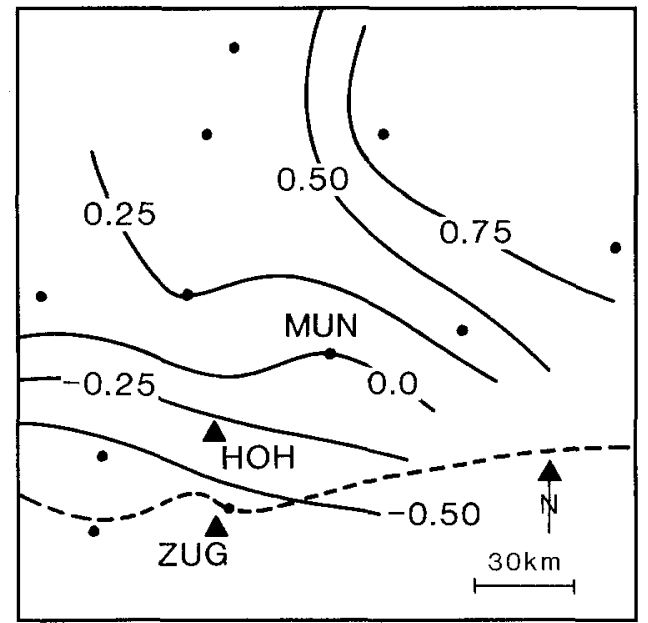

Fig. 3. Distribution of averaged horizontal pressure differences during foehn between 1974 and 1977. The isolines show the pressure differences between Munich and its surroundings in $\mathrm{mb}\left(p-p_{\mathrm{MUN}}\right)$. The dots indicate the synoptic stations from which data were used. The broken line indicates the northern baseline of the Alps. The abbreviations stand for: $\mathrm{HOH}$ (Hohenpeissenberg), MUN (Munich) and ZUG (Zugspitze) 
air towards the west in the shallow cold surface layer.

Applying the stationary, two-dimensional equation of motion;

$$
\begin{aligned}
& -f v=-\frac{1}{\rho} \frac{\partial p}{\partial x}-k u \\
& f u=-\frac{1}{\rho} \frac{\partial p}{\partial y}-k v
\end{aligned}
$$

where the advection term is also ignored. The frictional force is approximated by a linear approach, frequently used in simple land and sea breeze studies. The frictional coefficient $k$ is about $0.5 \cdot 10^{-3}$ $\mathrm{s}^{-1}$ and the Coriolis parameter $f$ is $10^{-4} \mathrm{~s}^{-1}$. Using a horizontal pressure gradient of $1.3 \mathrm{mb}$ $(100 \mathrm{~km})^{-1}$ directed from southwest to northeast we arrive at:

$$
\begin{aligned}
& v=13.0 \cdot\left(1+\alpha^{2}\right)^{-1} \\
& u=-\alpha v
\end{aligned}
$$

where $\alpha$ is $k / f$ and $u$ the velocity positive towards northeast and $v$ the velocity positive towards northwest. Finally, we get $v=0.5 \mathrm{~m} \mathrm{~s}^{-1}$ and $u=-2.5 \mathrm{~m} \mathrm{~s}^{-1}$. This rough estimate corroborates the advection qualitatively.

\section{The Synoptic Structure of Foehn}

In this section a brief comparison of the synoptic structures of the three foehn events are given in order to show that all three foehn events have similar characteristics, so allowing the comparison. of measurements taken on the three days.

Fig. 4 (left) shows the surface pressure charts of October 22, 1982, December 16, 1983 and October 3, 1984. In all cases there is a significant mesoscale trough on the lee side and a ridge of high pressure on the windward side. The surface maps show strong pressure gradients across the Alps between 3.0 and $4.2 \mathrm{mb}$ per $100 \mathrm{~km}$ (see Table 2). These gradients are taken between Munich and Udine. Using the gradients between stations located on the southern baseline of the Alps (Bolzano) and the northern baseline (Garmisch) we get stronger gradients between 6.1 (October 3, 1983 ) and $10.4 \mathrm{mb}$ per $100 \mathrm{~km}$ (October 22, 1982 , Dezember 16, 1983), suggesting that the foehn is stronger in autumn than in winter. However, this is not corroborated by observations. The foehn on October 22, 1982 was $20 \mathrm{~m} \mathrm{~s}^{-1}$ at Innsbruck, on December 16, $198315 \mathrm{~m} \mathrm{~s}^{-1}$ and on October $3,198412 \mathrm{~m} \mathrm{~s}^{-1}$. Part of the strong pressure gradient can be explained by the observed stagnation of cold air on the windward side of the mountain range. Assuming that at about summit level the pressure gradients across the barrier vanish, the surface pressure difference due to different airmasses on the two sides of the Alps can be estimated by

$$
\Delta p_{s}=-\left(h g \overline{p_{s}} / R \overline{T^{2}}\right) \Delta T .
$$

Here $p_{s}$ is the surface pressure and $T$ the vertical mean temperature in the layer $h$, which is the mountain height. The average over the lee and windward side is signified by an overbar. The vertical mean temperature are estimated by using the soundings of Munich and Milan for the surface layer of depth $\mathrm{h}$. With $h=3000 \mathrm{~m}$ we get surface pressure differences of about $2.6 \mathrm{mb}(22.10 .82)$, $6.8 \mathrm{mb}(16.1283)$ and $0.0 \mathrm{mb}(3.10 .82)$.

The vertical soundings taken at Munich 1200 GMT (Fig. 4, right) show that the low troposphere is very dry due to the drainage by the foehn. The upper troposphere on October 22, 1982 was very dry whereas the troposphere was humid during the other days. A weak to moderate flow in the troposphere comes from south to southwest during all foehn days (see Table 2).

All events are characterized by a strong surface inversion over Munich. The soundings also show elevated stable layers at $600 \mathrm{mb}$ (October 22, 1982, December 16, 1983) and at $700 \mathrm{mb}$ (October 3, 1984). The heights of the inversions are 390,560 and $600 \mathrm{~m}$. The depths of the inversion layers are 140,560 and $250 \mathrm{~m}$. Below the low-level inversion the wind comes from easterly directions at between two and three $\mathrm{m} \mathrm{s}^{-1}$ (Table 2). The winter case (December 16, 1983) is characterized by a thick cold surface layer between the ground and the inversion at $560 \mathrm{~m}$. During both autumn events, relatively thin elevated inversion layers of $140 \mathrm{~m}$ (October 22, 1982) and of $250 \mathrm{~m}$ (October 3, 1984) were observed $150 \mathrm{~m}$ and $350 \mathrm{~m}$ above ground, respectively. Both inversion layers were partly destroyed from below probably by solar heating.

In summary, we can say that all three foehn events are of similar characteristic with moderate flow aloft from south to west, with strong pressure gradients across the Alps, with a pool of cold air beneath an inversion and with westerly advection occurring in this cold air. 

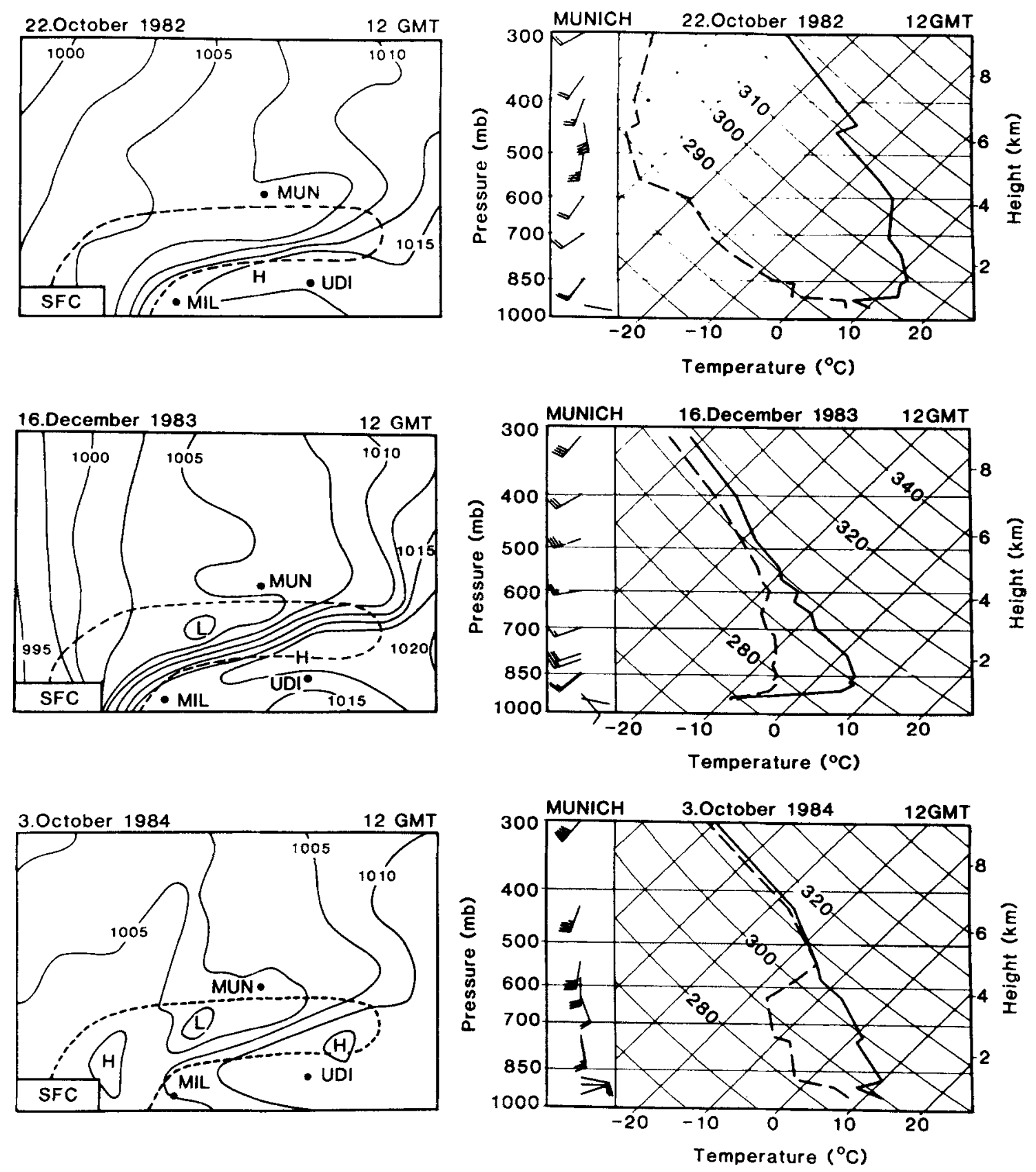

Fig. 4. Surface weather chart (left) on October 22, 1982 (top), December 16, 1983 (mid), October 3, 1984 (bottom) all at 1200 GMT. The broken line indicates the Alps. On the right are the 1200 GMT soundings at Munich (solid line, temperature; broken line, dewpoint temperature) for the same days. The oblique axis indicates potential temperature levels. The wind barbs at the left represent the wind speed $(k t)$ and wind direction using standard meteorological notation

\section{The Low-Level Flow}

On October 22, 1982, three instrumented aircraft made data-gathering flights in the northern lee of the Alps. In this section we present the analysis of this event to show the meso-scale flow on the lee side of the Alps. The Queenair flew between Munich and the Brenner-Pass, between two and five kms height. At the same time two motorgliders gathered data between Munich and the baseline of the Alps up to a height of $2.5 \mathrm{~km}$. The aircraft took temperature, pressure and humidity data. The temperature measurements are accurate to $0.3 \mathrm{~K}$, the dew-point to $1.0 \mathrm{~K}$ and the pressure to $0.25 \mathrm{mb}$. The sensitivities are $0.1 \mathrm{~K}, 0.05 \mathrm{~K}$ and $0.25 \mathrm{mb}$ respectively. For all aircraft, values were 
Table 2. Various Parameters Characterizing Three Foehn Events Calculated from Rawinsonde Soundings at Munich 1200 GMT and from Synoptic Data

\begin{tabular}{|c|c|c|c|}
\hline & 22 October ' 82 & 16 December ' 83 & 3 October " 84 \\
\hline \multicolumn{4}{|l|}{$\begin{array}{l}\text { Pressure gradient } \\
(\mathrm{mb} / 100 \mathrm{~km}):\end{array}$} \\
\hline Udine-Munich & 3.0 & 4.2 & 3.0 \\
\hline Bolzano-Garmisch & 10.4 & 10.4 & 6.1 \\
\hline Foehn/Innsbruck $\left(\mathrm{m} \mathrm{s}^{-1}\right)$ & 20.0 & 15.0 & 12.0 \\
\hline \multicolumn{4}{|l|}{ Munich 1200 GMT: } \\
\hline $\begin{array}{c}500 \mathrm{mb} \text { flow }\left(\mathrm{m} \mathrm{s}^{-1}\right) \\
(\mathrm{deg})\end{array}$ & $\begin{array}{l}14.0 \\
210\end{array}$ & $\begin{array}{l}13.0 \\
260\end{array}$ & $\begin{array}{l}14.0 \\
190\end{array}$ \\
\hline $\begin{array}{c}\text { Surface flow }\left(\mathrm{m} \mathrm{s}^{-1}\right) \\
(\mathrm{deg})\end{array}$ & $\begin{array}{c}1.0 \\
100\end{array}$ & $\begin{array}{l}1.0 \\
100\end{array}$ & $\begin{array}{l}2.5 \\
70\end{array}$ \\
\hline Height of the inversion (m) & 390 & 560 & 600 \\
\hline Depth of the inversion layer (m) & 140 & 560 & 250 \\
\hline Vertical shear $\left(\mathrm{m} \mathrm{s}^{-1} 100 \mathrm{~m}^{-1}\right)$ & 0.4 & 1.6 & 0.2 \\
\hline
\end{tabular}

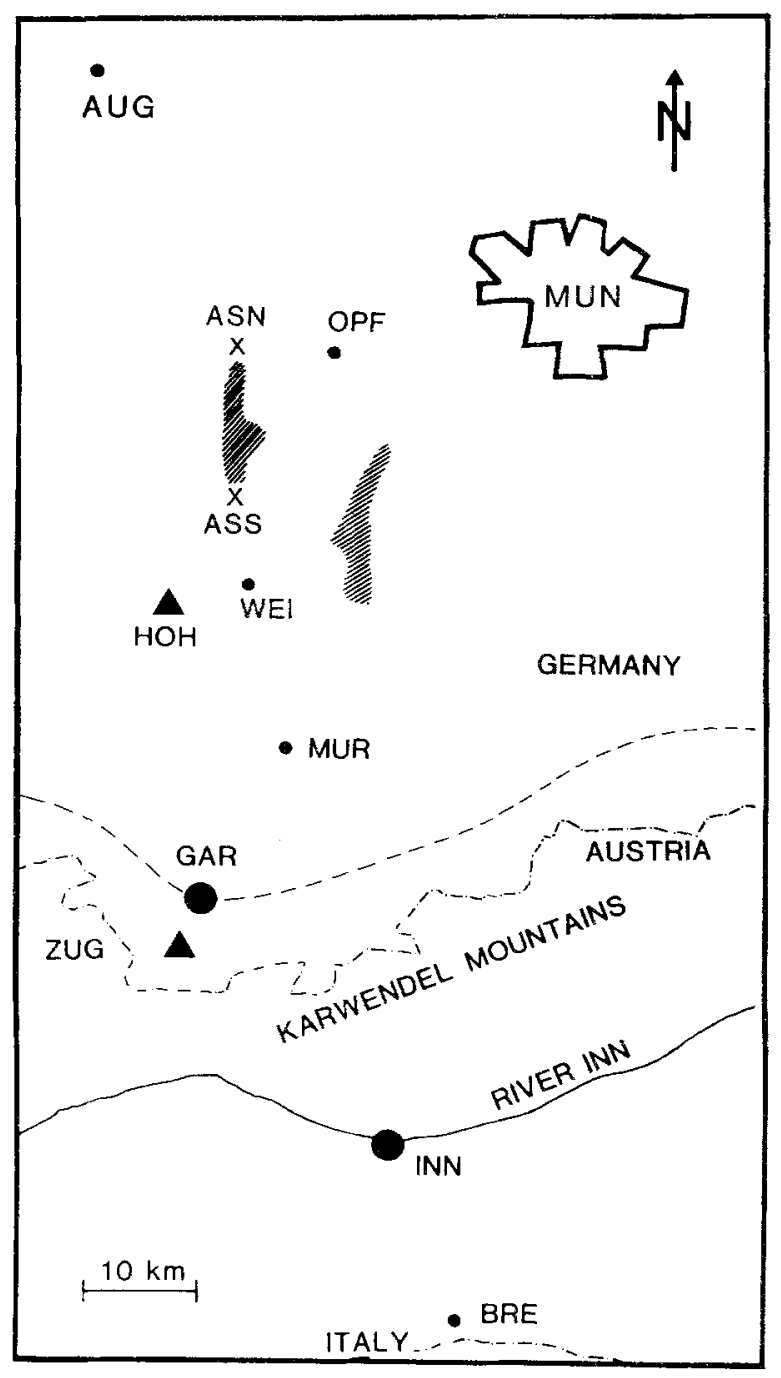

averaged over one second. Depending on the true ground speed one value represents a horizontal distance of about $50 \mathrm{~m}$ (Queenair) and $30 \mathrm{~m}$ (motorglider).

Figure 6 shows the analysed isentropic field between Munich and the Brenner-Pass. Above Innsbruck there is a wave approximately $50 \mathrm{~km}$ long with an amplitude of $1-2 \mathrm{~km}$. This wave is associated with small-scale lee waves. These waves occur downstream of a layer which is more stable than the layers above and below it. In this analysis the low-level stable layer is no longer evident downstream, above the area north of the baseline of the Alps, because the aircraft did not touch the very thin elevated stable layer found by the rawinsonde (Fig. 7).

In general, there are two different types of air flow across mountains. One is the regular lee wave type of flow whose significant feature is the regular lee wave pattern consisting of periodic oscillations with relatively short amplitudes and wave-lengths. This pattern usually is not associated with a strong

Fig. 5. Map showing the area north of the Alps. The dashed line indicates the baseline of the Alps. The abbreviations stand for: ASN (northern rim of the Ammersee), ASS (southern rim of the Ammersee), AUG (Augsburg), BRE (BrennerPass), GAR (Garmisch), HOH (Hohenpeissenberg), INN (Innsbruck), MUR (Murnau), OPF (Oberpfaffenhofen), WEI (Weilheim), ZUG (Zugspitze) 


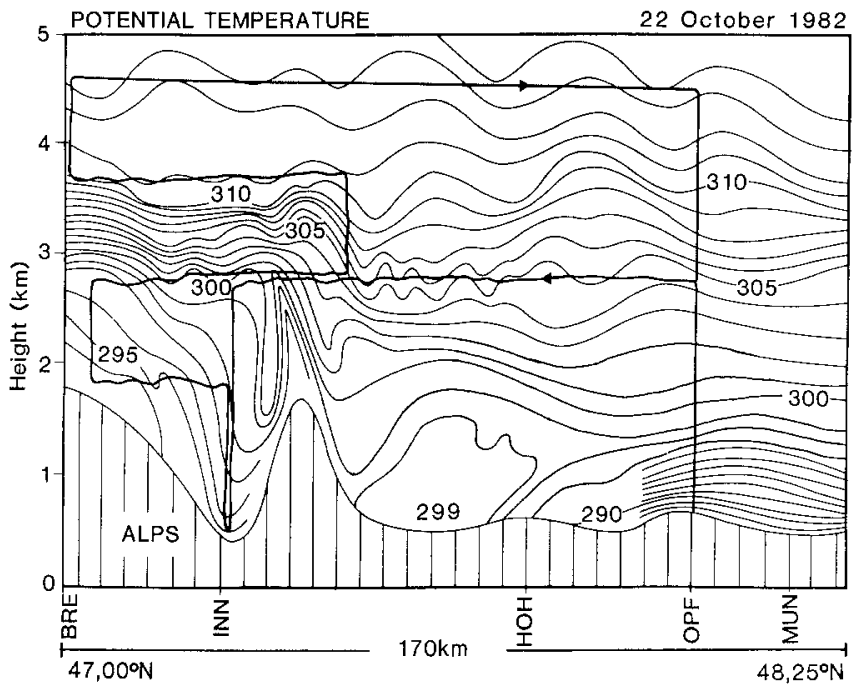

Fig. 6. Cross-sections of potential temperatures in $\mathrm{K}$ along a north-south line between the Brenner-Pass (BRE) and Munich (MUN) obtained from analysis of the data taken by the Queenair and the motorgliders on October 22, 1982. The thicker lines indicate the flight legs of the Queenair. The motorgliders made data gathering flights in the area between the baseline of the Alps and Oberpfaffenhofen between the surface and $2.5 \mathrm{~km}$

surface wind. This pattern can be seen in the troposphere north of the Alps. The observed surface wind in this area was weak, about $4 \mathrm{~m}$ $\mathrm{s}^{-1}$. The second observed pattern has a single prominent smooth downdraft regime just leeward of the main ridgeline and an abrupt turbulent updraft further downstream. A prominent example occurred during the famous Boulder storm (Klemp and Lilly, 1975). This pattern can be seen in the present case above the Inn valley with a smooth downdraft regime just leeward of the Brenner-Pass and an abrupt turbulent updraft north of Innsbruck. For this hydraulic jump type of flow, strong surface winds are to be expected. In this Innsbruck event, there were winds gusting up to $20 \mathrm{~m} \mathrm{~s}^{-1}$.

To give a rough estimate of the properties upstream south of the Alps in Fig. 7 (top), wind $(U)$, Brunt-Väisälä frequency $(N)$ and wind direction $(\alpha)$ are given for the troposphere above Milan. Winds in Milan were light easterly up to $2 \mathrm{~km}$, effectively the height of the Alps. Above this level, winds strengthened and backed up to southerlies. The downstream properties are shown in Fig. 7 (bottom). The wind sounding for Munich reveals that it increases in speed up to the $1500 \mathrm{~m}$ level and veers strongly between $500 \mathrm{~m}$ and $1000 \mathrm{~m}$.
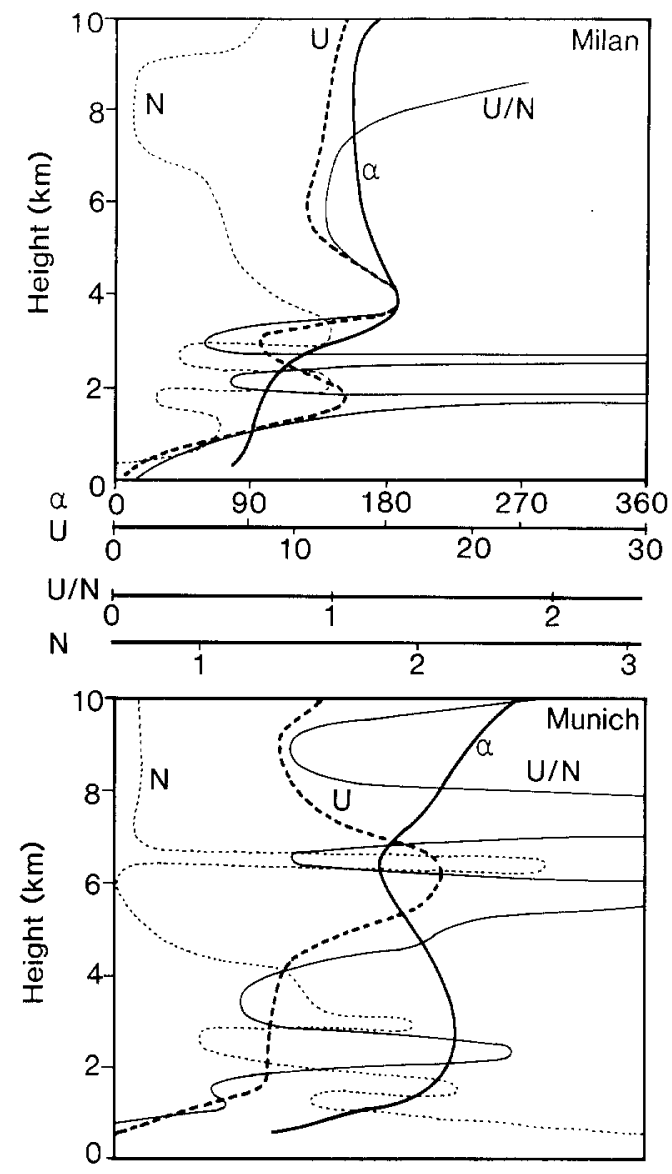

Fig. 7. Vertical profiles of wind speed $U\left(\mathrm{~m} \mathrm{~s}^{-1}\right)$, wind direction $a(\mathrm{deg})$, values $U / N(\mathrm{~km})$ and Brunt-Väisälä frequency $N\left(10^{-2} \mathrm{~s}^{-1}\right)$ as functions of height for Milan (top) and Munich (bottom) on October 22, 1982 at 1200 GMT

An important feature of the upstream sounding are two inversion layers located between 2 and $4 \mathrm{~km}$ on the upwind side of the mountain range. The Brunt-Väisälä frequencies in the upstream sounding at Milan are $0.010 \mathrm{~s}^{-1}, 0.016 \mathrm{~s}^{-1}$ and $0.010 \mathrm{~s}^{-1}$ in the layer below the elevated inversion, in the inversion layer and in the layer above the inversion, respectively. In wave observation it is well known that this low-level inversion at the level of the mountain top commonly provides an ideal environment for waves. Similar low-level inversions were observed during the Boulder storm case in 1972 (Klemp and Lilly, 1975) and during another foehn (Hoinka, 1985). The downwind stability profile also shows two stable layers at lower levels, as in the upwind profile. However, the base of the lower downwind layer, at about $1700 \mathrm{~m}$, is lower than the upwind base, at $2000 \mathrm{~m}$.

Another significant difference between the upwind and the downwind temperature profiles (not 
shown) is the steeper lapse rate for the downwind sounding, $-0.64 \mathrm{~K}$ per $100 \mathrm{~m}$, against $-0.49 \mathrm{~K}$ per $100 \mathrm{~m}$ on the upwind side, with higher potential temperatures at lower levels, as compared with the upwind profile. For chinook in Boulder the typical differences between the downwind and upwind soundings in the lapse rates are $-0.71 \mathrm{~K}$ per $100 \mathrm{~m}$ vs. $-0.57 \mathrm{~K}$ per $100 \mathrm{~m}$.(Brinkmann, 1974). The differences in lapse rate are the result of horizontal convergence, leading to divergence of streamlines in the vertical, with descending motion in the lower part of the disturbed flow and ascending motion above (Hoinka, 1985).

The isentropic field in the prealpine region again shows a layer of cold air close to the ground around Munich. At 1200 GMT a strong surface inversion existed over Munich (Fig. 6). The temperature profiles show that the warm air had not reached the ground. At the same time a potential temperature of $290.5 \mathrm{~K}$ was measured at the surface in Munich. The warm foehn air had eroded the cold surface layer between the baseline of the Alps and somewhere south of Munich. The analysis shows a block of relatively warm air (299 K) at low level in the area.

\section{The Temporal Development of the Inversion}

In this section we show the analysis of data gathered during a foehn event in order to determine the behaviour of the inversion between the northern baseline of the Alps and Munich. On December 16, 1983 two motorgliders and a Queenair ascended and descended several times within about two hours over four places on a baseline perpendicular to the Alps and spaced about $20 \mathrm{~km}$ apart. These locations are: Murnau, Weilheim and the southern and northern rim of the Ammersee (Fig. 5). This set-up was designed to determine the inclination of the inversion and the erosion of the surface layer by the overriding foehn.

Fig. 8 shows the change with time of the potential temperature above these four locations
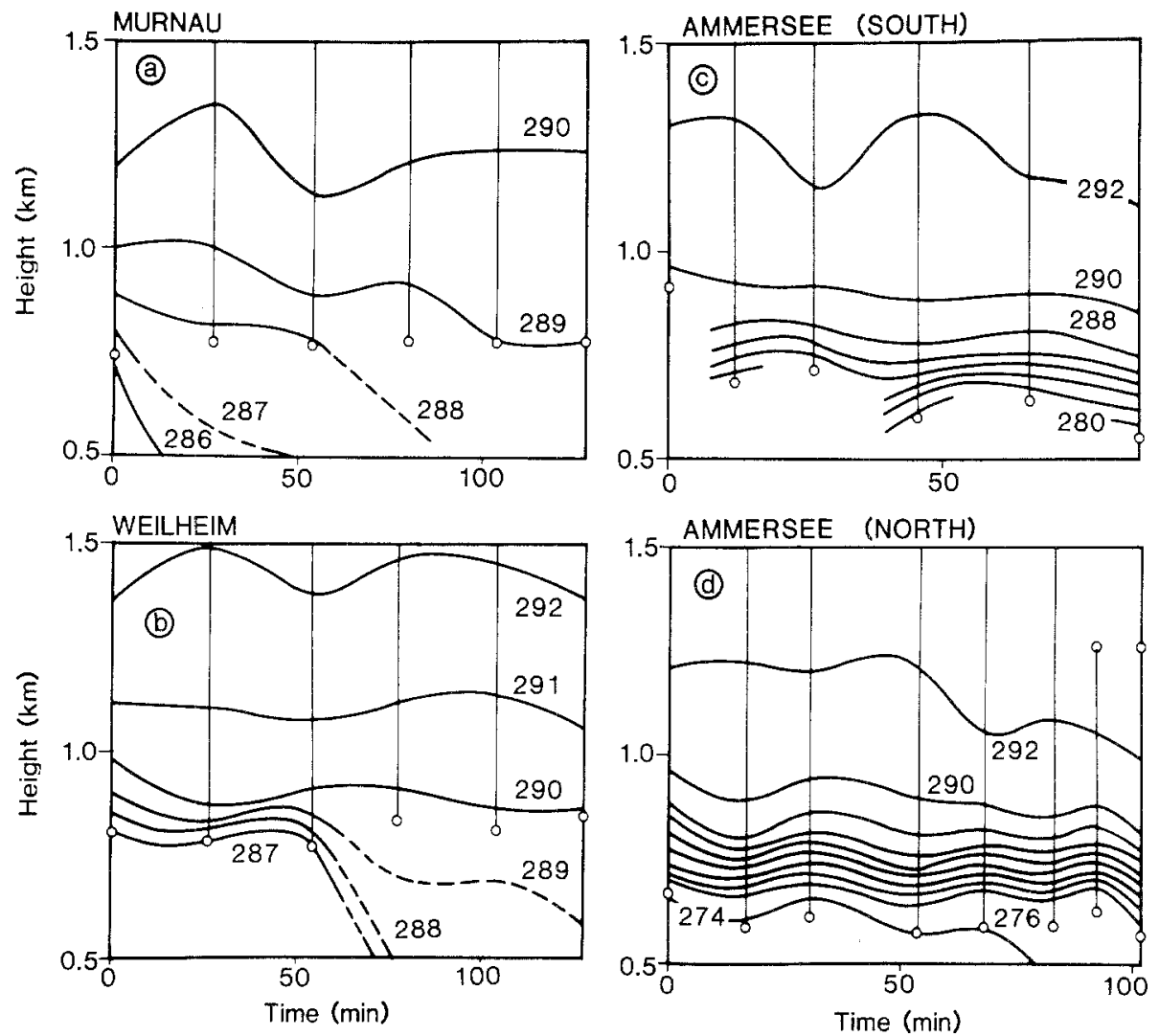

Fig. 8. The development of the potential temperature field in $\mathrm{K}$ sampled by the Queenair and the motorgliders on December 16, 1983. The structures shown are above Murnau (a), Weilheim (b), southern rim of the Ammersee (c) and northern rim of the Ammersee (d). The starting times of all the first soundings are between 1120 and $1140 \mathrm{GMT}$. The circles mark the lowest and highest points at which measurements were made 

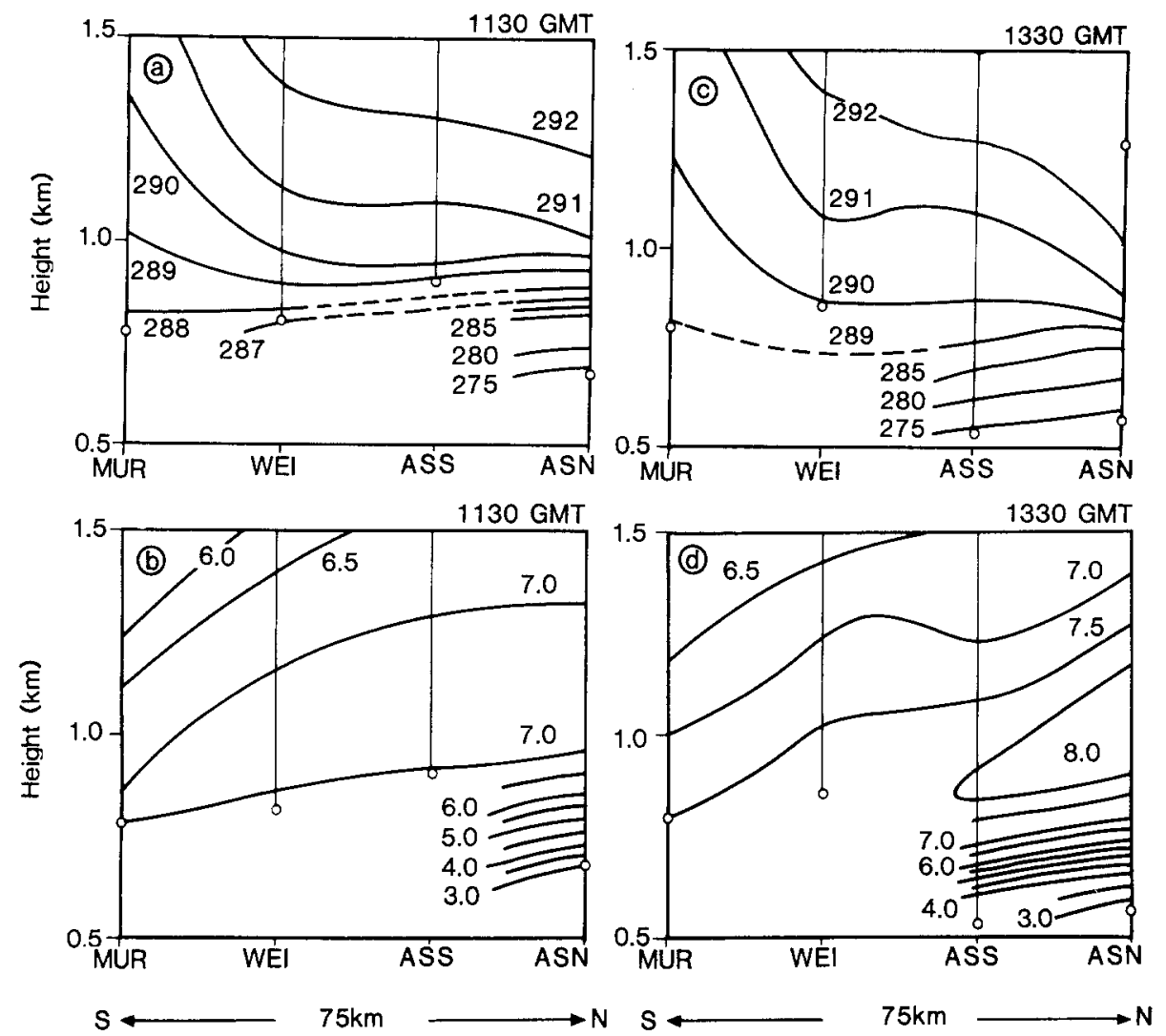

Fig. 9. Cross-sections of potential temperature in $\mathrm{K}(a, c)$ and mixing ratio in $\mathrm{g} \mathrm{kg}^{-1}(b, d)$ between Murnau (MUR) and the northern rim of the Ammersee (ASN) on December 16, 1983. The cross-sections are shown at $1130(a, b)$ and at $1330 \mathrm{GMT}$ $(c, d)$

north of the Alps. All cross-sections were started at about $1130 \mathrm{GMT}$. No inversion is apparent above Murnau, the southernmost location: the foehn air has touched the ground (a). At Weilheim (b), about $20 \mathrm{~km}$ further north, there is initially an inversion about $300 \mathrm{~m}$ above ground, which was eroded by the foehn about one hour later. The inversion is preserved during the entire observation, from about $20 \mathrm{~km}$ north (c) and also $50 \mathrm{~km}$ north (d), but the cold surface layer tends to become progressively shallower. The inversion layer is more pronounced and higher above the northernmost location (d) than $20 \mathrm{~km}$ south of it (c).

The spatial distribution of the isentropes and of the mixing ratios are given in Fig. 9 for two different times: at $1130 \mathrm{GMT}$ (left) and at 1330 GMT (right). The first time is about the starting time of the observation period and the last time is the time of the final soundings. Northwards descending isentropes above one $\mathrm{km}$ height indicate that the air subsides in this area during foehn. Within the two hours when measurements were made, the structure remains about constant. The mixing ratios $(b, d)$ have increased in the northernmost part to up to $8 \mathrm{~g} \mathrm{~kg}^{-1}$ above the inversion; again strong changes have not occurred. The mixing ratios beneath the inversion are about $50 \%$ of the amount of the mixing ratios above it. This confirms that the inversions are effective barriers against exchanges of moisture.

The erosion of the cold surface layer by the overriding foehn is detectable by a lowering of the height of the inversion layer. The temporal evolution of the inversion can easily be measured by a SODAR. Fig. 10 shows the SODAR observations at Oberpfaffenhofen. Between 1000 and $1400 \mathrm{GMT}$ the interface undulates vertically with variations of about $100 \mathrm{~m}$ and a period of about one hour. These undulations suggest that during this time Kelvin-Helmholtz-waves have occurred at the interface above Oberpfaffenhofen. However, the period of these waves was too short to be detected by the aircraft measurements because the interval between different soundings taken by the aircraft was about 25 minutes. 


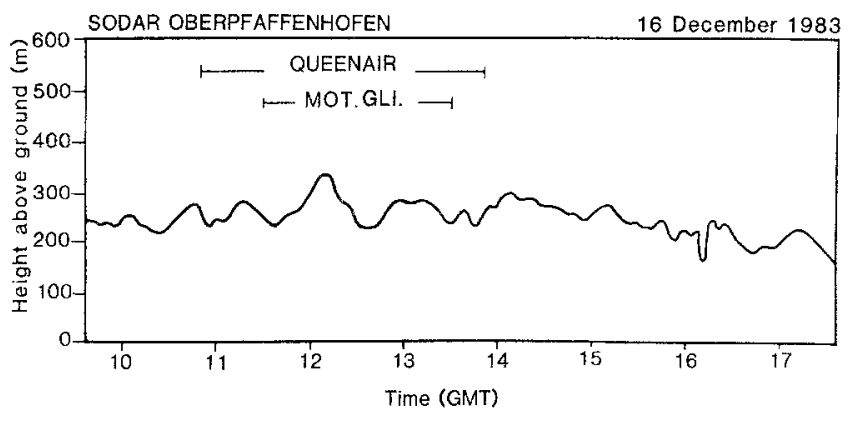

Fig. 10. The change over time of the inversion height above Oberpfaffenhofen measured by SODAR on December 16 , 1983. The observation times of the Queenair and of the motorgliders are indicated

In the morning the averaged height of the interface is about $250 \mathrm{~m}$ above ground dropping in the afternoon to about $150 \mathrm{~m}$. This lowering of the interface corroborates the aircraft observations. The decrease in depth suggests that the surface layer has been eroded by the overriding foehn or by surface heating. Similar observations by Bedard (1982) in Boulder showed that the erosion rate, estimated from SODAR records, is a good predictor of the arrival of the chinook at the surface within two to four hours. However, in a different case Mathews etal. (1984) showed that in Alberta it was difficult to predict the arrival of warm air at ground level from simple extrapolation of the height-time variation of elevated echolayers associated with chinook.

Table 3. The Mean Squares of the Vertical Acceleration Measured Along a Layer $A p$ Below and Above the Inversion on December 16, 1983. The last value is the average over all data

Below Above

the Inversion

\begin{tabular}{rllr}
\hline $\begin{array}{c}\Delta p \\
\mathrm{mb}\end{array}$ & $\begin{array}{l}\left(g^{\prime 2}\right)^{0.5} \\
\mathrm{~m} \mathrm{~s}^{-2}\end{array}$ & $\begin{array}{l}\left(g^{2}\right)^{0.5} \\
\mathrm{~m} \mathrm{~s}^{-2}\end{array}$ & $\begin{array}{c}\Delta p \\
\mathrm{mb}\end{array}$ \\
\hline 6 & 0.135 & 0.259 & 5 \\
7 & 0.178 & 0.251 & 10 \\
6 & 0.081 & 0.187 & 8 \\
14 & 0.213 & 0.329 & 13 \\
8 & 0.121 & 0.255 & 5 \\
12 & 0.236 & 0.139 & 17 \\
8 & 0.169 & 0.279 & 5 \\
14 & 0.166 & 0.279 & 13 \\
5 & 0.102 & 0.288 & 4 \\
10 & 0.109 & 0.174 & 11 \\
& 0.151 & 0.244 & \\
\hline
\end{tabular}

Although no turbulence measuring instruments were available on board of the aircraft, it was noted that the warm air was sometimes more turbulent than the cold air beneath the inversion. Nevertheless the motorgliders have a system on board to measure the vertical acceleration $g^{\prime}$ where the prime denotes deviations from the gravitational acceleration. After filtering, we have evaluated the mean squares of the vertical acceleration in a thin layer beneath and above the inversion. In Table 3 the $\left(g^{\prime 2}\right)^{0.5}$ are given for various ascents and descents through the inversion layer above the southern and the northern rim of the Ammersee. In most cases this measure is twice the size above the inversion than beneath it, indicating that the atmosphere is in a slightly more turbulent state above the inversion.

\section{The Trapping of Polluted Air}

In the cold surface layer at Munich advection from the east occurs. This flow advects an urban-produced plume westwards from Munich and causes a narrow strip of polluted air extending westward away from Munich. In this section we discuss measurements made across this plume during the foehn on October 3, 1984. Five cross-sections approximately perpendicular to the east-west plume of polluted air were flown with increasing distance from the main pollutor, Munich, measuring NO and $\mathrm{NO}_{\mathrm{x}}$ concentrations, where the $\mathrm{NO}_{\mathrm{x}}$ are the sum of the $\mathrm{NO}$ and $\mathrm{NO}_{2}$ concentrations. The

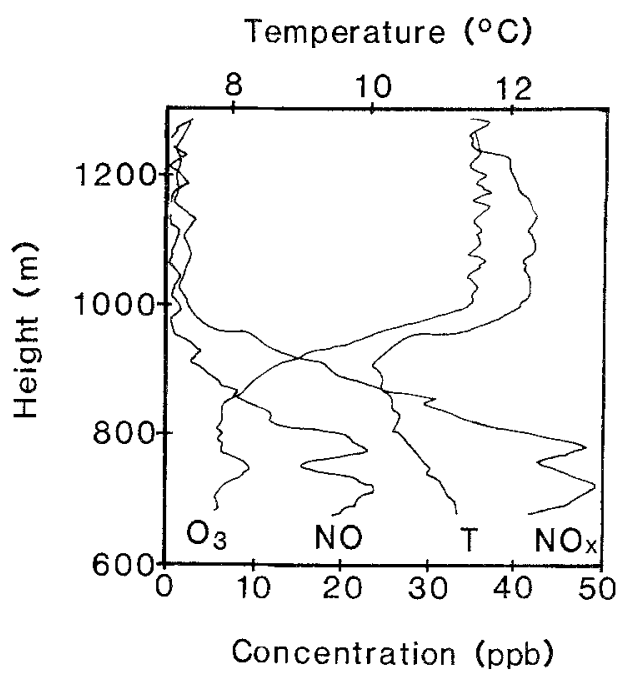

Fig. 11. Vertical sounding about $60 \mathrm{~km}$ west of Munich on October 3, 1984 at 1230 GMT taken by the Queenair. The temperature $(T)$, ozone $\left(\mathrm{O}_{3}\right)$, $\mathrm{NO}$ and $\mathrm{NO}_{\mathrm{x}}$ values are given 
whole programme takes about 3 hrs flying time. The Queenair is equipped with a chemiluminescence analyzer to measure $\mathrm{NO}$ and $\mathrm{NO}_{\mathrm{x}}$ concentrations with an accuracy of $1.4 \%$ and a sensitivity of $2 \mathrm{ppb}$. The aircraft flew at $800 \mathrm{~m}$ MSL which is between 250 and $400 \mathrm{~m}$ above ground, which shows that the air was sampled within the cold surface layer as can be seen in Figs. 4 and 11 .

Fig. 11 shows a vertical profile taken by the aircraft about $60 \mathrm{~km}$ west of Munich. For this vertical sounding ozone measurements were also made. At the main inversion layer at $950 \mathrm{~m} \mathrm{MSL}$ strong vertical gradients of all constituents occur. Beneath the inversion the background ozone of about $35 \mathrm{ppb}$ drops to $5 \mathrm{ppo}$, whereas the background values of $\mathrm{NO}$ and $\mathrm{NO}_{\mathrm{x}}$ of about $2 \mathrm{ppb}$ increase to 20 and $45 \mathrm{ppb}$, respectively. In the cold surface layer ozone was reduced by reaction with $\mathrm{NO}$ forming $\mathrm{NO}_{2}$ and $\mathrm{O}_{2}$. Under certain (chemical) conditions and in direct sunlight irradiation ozone is generated by photochemical processes. However, because on October 3, 1984 about $7 / 8$ cloudiness was observed in the Munich area during the entire day, the amount of ozone produced photochemically in the plume is insignificant, so the $\mathrm{NO}_{2}$ was generated only from the background ozone. Therefore on that day there was a significant reduction of ozone in the surface layer. Strong inversions are known to be effective in trapping constituents. Even weak inversions apparent in the temperature profile (Fig. 11) at 750 and $850 \mathrm{~m} \mathrm{MSL}$ are able to block the vertical exchange of $\mathrm{NO}$ and $\mathrm{NO}_{\mathrm{x}}$. This causes a change of concentration up to $25 \%$ within $50 \mathrm{~m}$ or less.

The spatial distribution of the NO-concentration determined by the Queenair measuring-system west of Munich on October 3, 1984 is given in Fig. 12. It shows that the concentration increases significantly from about $10 \mathrm{ppb}$ to $50 \mathrm{ppb}$ within $10 \mathrm{~km}$ as the polluted air is entered from the south. As expected leaving the plume towards north, the concentrations drop again to about $10 \mathrm{ppb}$. Surprisingly the gradients towards the north are weaker in magnitude than the southern ones. That might be an effect of local windsystems. The $\mathrm{NO}_{\mathrm{x}}$ pattern (full line) closest to Munich $(10 \mathrm{~km})$ show large small-scale variations which are due to the particular distribution of emission sources in the Munich area. The second traverse (long-dashed line) downwind of Munich $(20 \mathrm{~km}$ ) shows less small-scale variations indicating that

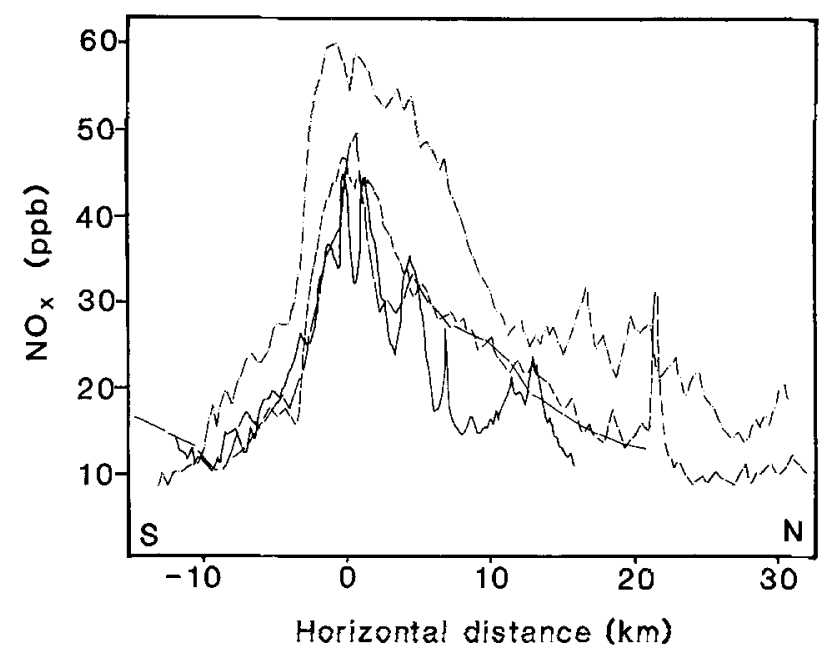

Fig. 12. The spatial distribution of NO-concentrations taken by the Queenair west of Munich on October 3, 1984 between 1100 and $1400 \mathrm{GMT}$. The baselines of the flight tracks are given in Fig. 13. The full, long-dashed, short-dashed and dashed-dotted lines show the concentrations at a distance of $10,20,30$ and $55 \mathrm{~km}$ from Munich, respectively

small-scale horizontal mixing has occurred. An additional small-scale peak is apparent in the $30 \mathrm{~km}$ traverse (short-dashed line) which indicates the emission of NO on a highway running westeast in this area. The general pattern seems to be stationary over a reasonable time. This is corroborated by comparing two patterns measured $30 \mathrm{~km}$ away from Munich which were taken about $1.5 \mathrm{hrs}$ apart. The concentrations remain unchanged. In Fig. 12 only one pattern is shown (short-dashed line).

A rough image of the horizontal distribution of $\mathrm{NO}_{\mathrm{x}}$ is given in Fig. 13 (top) emphasizing the tongue-like character of the plume west of $\mathrm{Mu}$ nich. Surprisingly the highest concentrations are found about $55 \mathrm{~km}$ west of Munich at the flight level of about $400 \mathrm{~m}$ above ground. A possible explanation is that on that day the stratification close to the surface was very stable. This together with the low wind velocity (about $2.5 \mathrm{~m} / \mathrm{s}$ ) almost inhibits vertical mixing. Therefore it takes about $50 \mathrm{~km}$ to mix the polluted air vertically. This means that the concentrations measured at this flight level might not be equivalent to those which are expected at the surface downwind close to the pollutor.

The ratio $\mathrm{NO} / \mathrm{NO}_{\mathrm{x}}$ is usually considered to be a measure of the time passed since the emission of the NO, because NO is destroyed by ozone. 

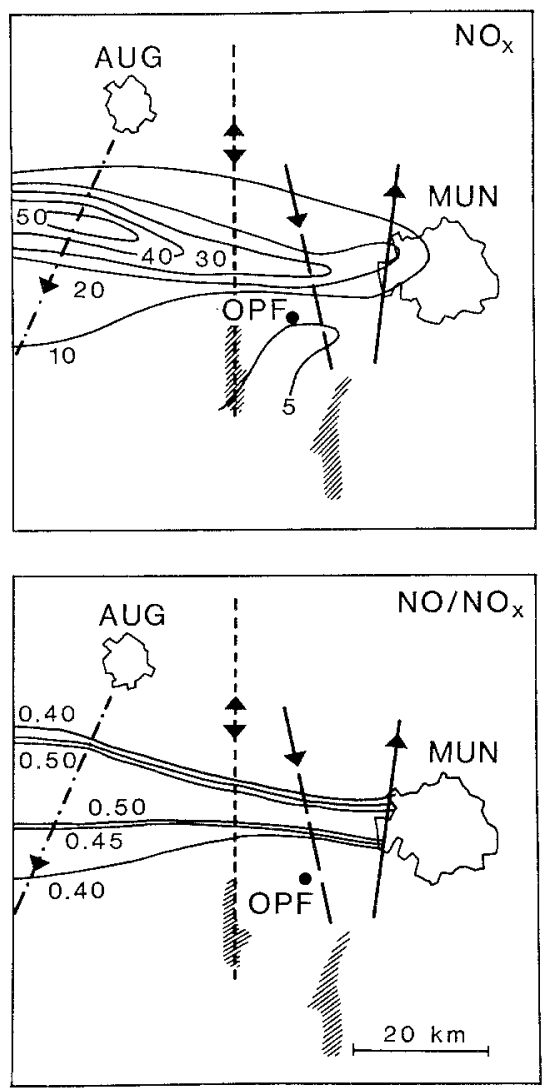

Fig. 13. Horizontal distribution of $\mathrm{NO}_{\mathrm{x}}$ (top) in $\mathrm{ppb}$ and of the ratio $\mathrm{NO} / \mathrm{NO}_{\mathrm{x}}$ (bottom) on October 3, 1984. The lines indicate the flight tracks where measurements were made

Therefore the ratio $\mathrm{NO} / \mathrm{NO}_{\mathrm{x}}$ should decrease with increasing distance from the pollutor. In the present event this is not the case (Fig. 13, bottom), the ratio remains constant along the main axis of the plume. The constant ratio $\mathrm{NO} / \mathrm{NO}_{\mathrm{x}}$ is due to the fact that in the polluted air the concentration of ozone was too low to oxidize all the NO. This is corroborated by the very low concentration shown in the vertical profile $60 \mathrm{~km}$ west of Munich (Fig. 11). Also the horizontal entrainment of ozone at the northern and southern rim of the plume is negligible which can be seen in the strong gradients of the ratio $\mathrm{NO} / \mathrm{NO}_{\mathrm{x}}$.

\section{Conclusions}

The present study documents observed features of the troposphere above the low-level inversion during foehn, observed features of the behaviour of the inversion itself, and observed features of the trapping of pollution beneath it.

In a climatology, covering four years, the upper level wind is compared with the low-level surface wind, showing that in a large number of foehn events a weak westward flow occurs in the cold surface layer beneath the southerly flow. This advection of cold air occurs because a strong mesoscale pressure gradient of more than $1 \mathrm{mb}$ per $100 \mathrm{~km}$ in magnitude exists north of the Alps pointing towards the north-east during foehn.

During three foehn events various aircraft made data gathering flights. The isentropic field, analysed from aircraft data, taken in the lower troposphere above and below the low-level leeside inversion, shows that the foehn has touched the ground about $30 \mathrm{~km}$ north of the baseline of the Alps. Further north $(20 \mathrm{~km})$ and especially $50 \mathrm{~km}$ the further north, the inversion layer remains the entire day and foehn air does not touch the ground. A slight descent of the inversion layer is observed.

From the present observation it is not possible to give some estimate of the rate of northward retreat of the surface tip of the cold air during the two-hour observational period. The non-arrival of the foehn in Munich prompts the question of what determines the northern limit of the surface penetration of the foehn. These two interesting issues could be studied by doing further observational work and by using a meso-scale model which must include eddy mixing processes, gravity wave flux parameterisation and surface heating.

\section{Acknowledgements}

The scientific observers on board of the aircraft were Wolfgang Peters, Thomas Jank and Hermann Willeke (all from DFVLR). They also carried out the data processing. Reinhold Steinacker (University of Innsbruck) and his colleagues were very helpful with their advice in predicting the foehn. They also launched a rawinsonde in the Inn valley. Gertraud Jacob is thanked for the excellent job she did in preparing the drawings.

\section{References}

Bedard, J. B., 1982: Sources and detection of atmospheric wind shear. AIAA Journal, 20, 940-945.

Brinkmann, W. A. R., 1974: Strong downslope winds at Boulder, Colorado. Mon. Wea. Rev., 102, 592-602.

Hoinka, K. P., 1985: Observation of the airflow over the Alps during a foehn event. Quart. J. Roy. Meteor. Soc., 111, 199-224.

Holmes, R. M., Hage, K. D., 1971: Airborne observations of three chinook-type situations in southern Alberta. $J$. Appl. Meteor., 10, 1138-1153.

Klemp, J. B., Lilly, D. K., 1975: The dynamics of waveinduced downslope winds. J. Atmos. Sci., 32, 320-339. 
Mathews, T., Lester, P. E., Hicks, R. B., 1984: Sodar observations of chinook and Arctic front passages across the eastern slopes of the Canadian Rockies. AtmosphereOcean, 22, 328-342.

Nater, W., Richner, H., Phillips, P. D., 1979: Shear instabilities and their characteristics during foehn. Geophys. Astrophys. Fluid Dynamics, 13, 215-223.
Nkemdirim, L. C., Leggat, K., 1978: The effect of chinook weather on urban heat islands and air pollution. Water, Air and Soil Pollution, 9, 53-67.

Authors' address: Dr. K. P. Hoinka and F. Rösler, Institut für Physik der Atmosphäre DFVLR, D-8031 Oberpfaffenhofen, Federal Republic of Germany. 